\title{
ANALISIS EKSTRAKS CIRI FERTILITAS TELUR AYAM KAMPUNG DENGAN GREY LEVEL COOCCURRENCE MATRIX
}

\author{
Shoffan Saifullah ${ }^{1 *}$, Sunardi ${ }^{2}$ dan Anton Yudhana ${ }^{3}$ \\ ${ }^{1}$ Teknik Informatika, Pascasarjana Teknik, Universitas Ahmad Dahlan \\ 2,3Jurusan Teknik Elektro, Fakultas Teknologi Industri, Universitas Ahmad Dahlan \\ *Corresponding author, e-mail: shoffan_s@yahoo.com
}

\begin{abstract}
Abstrak - Penelitian ini menggunakan telur ayam kampung untuk melakukan analisis dalam proses identifikasi fertilitas telur ayam. Metode dalam proses identifikasi menggunakan Gray Level Coocurence Matrix (GLCM). Proses identifikasi dengan menggunakan GLCM menggunakan 6 parameter utama untuk mengetahui ciri-ciri (ekstraksi ciri). Parameter yang digunakan yaitu: ASM (Angular Second Moment), Kontras, Korelasi, Varians, IDM (Inverse Difference Moment), dan Entropy. Masing-masing parameter akan memberikan nilai yang berbeda dan mampu membedakan dan mengelompokkan citra telur ayam kampung berdasarkan fertilitas telur ayam. Proses identifikasi memberikan hasil bahwa fertilitas pada citra telur ayam kampung mampu dibedakan dengan parameter-parameter GLCM dan menunjukkan bahwa dengan menggunakan 10 sampel telur ayam kampung mampu dikelompokkan berdasaarkan fertilitasnya.
\end{abstract}

\section{Kata Kunci : Telur ayam kampung, Ekstraksi Ciri, Parameter GLCM}

\begin{abstract}
This research used chicken eggs to perform the analysis in the identification process fertility chicken eggs. The method in the identification process using Gray Level Co-occurrence Matrix (GLCM). The identification process by using GLCM using the 6 main parameters to determine the characteristics (feature extraction). The parameters used are: ASM (Angular Second Moment), Contrast, Correlation, Variance, IDM (Inverse Difference Moment), and Entropy. Each parameter will give different values and is able to distinguish and classify images based fertility chicken eggs chicken eggs. The identification process gives results that the image of a chicken egg fertile and infertile able to distinguish from GLCM parameters and show that using 10 samples of chicken eggs able to be grouped based on their fertility.
\end{abstract}

Keywords: Chicken Eggs, Feature Extraction, GLCM Parameters

Copyright $@ 2017$ JNTE. All rights reserved

\section{PENDAHULUAN}

Telur merupakan benda bercangkang yang mengandung zat hidup bakal anak yang dihasilkan oleh unggas (ayam, itik, burung, dan sebagainya)[1]. Telur yang dihasilkan oleh unggas bermaca-macam misalnya adalah ayam kampung. Ayam kampung (Gallus Domesticus [2],[3]) merupakan sebutan ayam peliharaan di Indonesia yang tidak dibudidayakan dengan cara budidaya massal komersial dan tidak berasal usul dari ras yang dihasilkan untuk kepentingan komersial.

Proses penentuan kualitas sebelum dilakukan penetasan yang sering dilakukan untuk mengetahui tingkat kualitas telur ayam dilakukan dengan merendam telur pada wadah berisi air pada suhu ruang[4]. Pengecekan fertilitas telur ayam dilakukan dengan proses candling/peneropongan telur ayam dengan menggunakan cahaya. peneropongan telur yang berfungsi untuk mengetahui telur yang infertile (tidak dibuahi), telur yang fertile, embrio yang tumbuh dan embrio yang mati[5],[6].

Proses identifikasi yang dilakukan sering menggunakan proses manual sehingga akan lebih membutuhkan ketelitian yang lebih dari orang yang melakukan proses identifikasi tersebut. Untuk memudahkan dalam melakukan identifikasi maka penelitian ini akan memberikan kontribusi dalam analisis proses identifikasi fertilitas telur ayam kampung dengan menggunakan gray level coocurence matrix (GLCM) untuk melakukan digital image processing. Beberapa peneliti telah melakukan berbagai penerapan untuk melakukan identifikasi fertilitas telur (terlihat pada Gambar 1). Dalam proses penelitian yang dilakukan menggunakan beberapa perangkat yaitu 


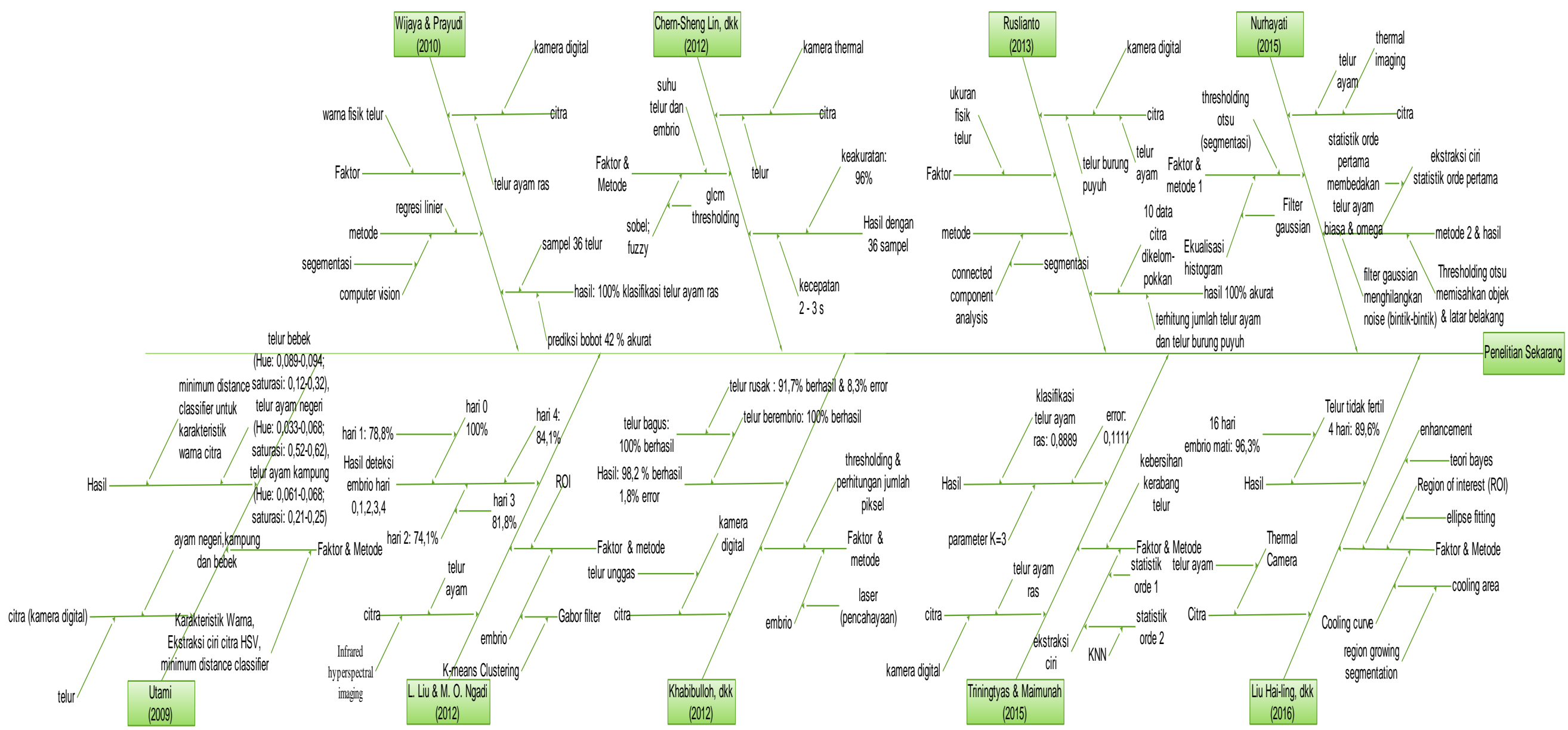

Gambar 1. Fishbone Diagram Penelitian Terdahulu[8],[9], [10][11][12][13][14][15][16] 
kamera smartphone dan senter. Kamera smartphone digunakan untuk proses akuisisi citra atau untuk mengambil gambar telur ayam yang dilakukan proses candling. Sedangkan untuk senter digunakan untuk proses candling atau menerangi telur ayam sehingga bagian dalam telur akan terlihat lebih jelas. Proses akuisisi dan candling telur dilakukan di tempat yang gelap dengan tujuan agar memberikan gambar isi telur secara jelas.

Penelitian ini diharapkan mampu mengidentifikasi dengan akurat telur yang berembrio (fertile) maupun tidak, dan dapat membantu memudahkan peternak dalam memilah telur.

\section{TINJAUAN PUSTAKA}

Citra merupakan fungsi menerus (continue) dari intensitas pada bidang 2 dimensi (sudut pandang matematis). Citra tampak merupakan hasil refleksi cahaya dari objek nyata. Cahaya akan menerangi objek, dimana objek akan memantulkan kembali ke sebagian dari berkas cahaya tersebut, dan pantulan cahaya akan ditangkap oleh optik, misalnya kamera, kemudian direkam [7].

Penelitian tentang identifikasi fertilitas telur sudah banyak dilakukan (terlihat pada Gambar 1). Penelitian yang akan dilakukan adalah melakukan roses analisis ekstrasi ciri dari citra telur ayam kampung dengan menggunakan metode GLCM.

\subsection{Fertilitas Telur}

Fertilitas (kesuburan) telur merupakan sebuah indikator ada tidaknya embrio dalam telur[17]. Fertilitas suatu kelompok telur menunjukkan banyaknya telur yang bertunas dari sejumlah telur yang dieramkan. Maksud dari tunas dalam hal ini adalah bibit atau lembaga telur. Misalkan ada sebuah telur diperiksa dengan lampu (proses penyinaran/ candling) ternya terdapat bibit di dalamnya, maka telur tersebut adalah fertile[18].

\subsection{Histogram}

Histogram citra sangat berkaitan dengan ber-bagai teknik pengolahan citra, terutama metode-metode yang tergolong dalam operasi titik.

Histogram citra merujuk pada histogram dari nilai intensitas pixel. Histogram menampilkan banyaknya piksel dalam suatu citra yang dikelompokkan berdasarkan level nilai intensitas piksel yang berbeda. Pada citra grayscale 8 bit, terdapat 256 level nilai intensitas yang berbeda, maka pada histogram tersebut akan menampilkan grafik distribusi dari masingmasing 256 level nilai piksel tersebut[19].

Histogram didefinisikan sebagai probabilitas statistik distribusi setiap tingkat abu-abu dalam gambar digital. Persamaan histogram (Histogram Equalization/HE) merupakan teknik yang sangat populer untuk peningkatan kontras gambar. Konsep dasar dari histogram equalization adalah dengan menstrecth histogram, sehingga perbedaan piksel menjadi lebih besar atau dengan kata lain informasi menjadi lebih kuat sehingga mata dapat menangkap informasi yang disampaikan.

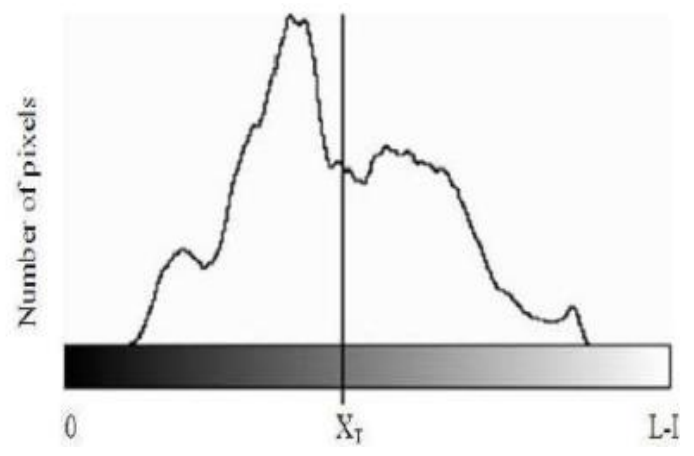

Gambar 2. Grafik Histogram[20]

Citra kontras ditentukan oleh rentan dinamis, yang didefinisikan sebagai perbandingan antara bagian paling terang dan paling gelap intensitas piksel. Histogram memberikan informasi konstras dan intensitas keseluruhan distribusi dari suatu gambar[20].

Histogram dengan jarak dari 0 sampai L-1 dibagi menjadi 2 bagian, dengan XT sebagai intensitas. Pemisahan ini menghasilkan 2 histogram. Histogram pertama memiliki jangkauan dari 0 sampai XT, dan histogram kedua memiliki jangkauan dari XT sampai L$1[20]$.

\subsection{Ekstraksi Ciri}

Ekstraksi ciri merupakan langkah awal dalam proses klasifikasi dan inpretasi citra, dimana proses ini berhubungan dengan kuantisasi karakteristik citra kedalam kelompok nilai ciri yang sesuai. Analsis tektur biasanya dilakukan sebagai proses untuk melakukan 
klasifikasi dan interpretasi suatu citra. Klasifikasi citra berbasis analisis tekstur memerlukan beberapa tahapan[14].

Berdasarkan orde statistiknya, analisis tekstur dapat dikategorikan menjadi 3, yaitu analisis tekstur orde satu, orde dua, dan orde tiga. Untuk penelitian ini digunakan ekstraksi ciri statistik orde dua yaitu dengan metode Gray Level Coocurence Matrix (GLCM).
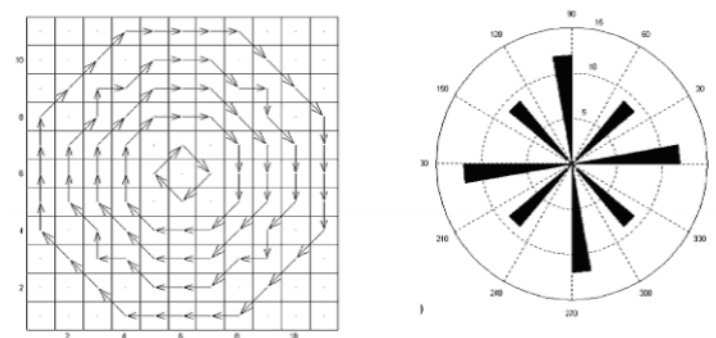

Gambar 3. PerputaranVektor GLCM dan Diagram Rose[21]

Gambar 3 menunjukkan arah dan perputaran vektor GLCM yang mengikuti kontur melingkar sesuai dengan gravitasi dan mampu membantu mendeteksi fitur melingkar dan linier pada setiap orientasi[21].

Dalam perhitungan GLCM terdapat beberapa fitur atau parameter perhitungan sebagai berikut[22]:

\section{ASM (Angular Second Moment)}

Mengukur tentang keseragaman atau sering disebut angular second moment. Energi akan bernilai tinggi ketika nilai piksel mirip satu sama lain, sebaliknya akan bernilai kecil menandakan nilai dari GLCM normalisasi adalah heterogen. Nilai maksimum dari energy adalah 1 yang artinya distribusi pixel dalam kondisi konstan atau bentuknya yang berperiodik (tidak acak).

$A S M=\sum_{i, j=0}^{N-1} p(i, j)^{2}$

2. Kontras

Mengukur frekuensi spasial dari citra dan perbedaan moment GLCM. Perbedaan yang dimaksudkan adalah perbedaan tinggi dan rendahnya pixel. Contrast akan bernilai 0 jika pixel ketetanggaan mempunyai nilai yang sama.
Kontras $=\sum_{i, j=0}^{N-1}(i-j)^{2} p(i, j)$

3. Korelasi

Mengukur linearitas (the joint probability) dari sejumlah pasangan pixel (pairs).

$$
\text { Korelasi }=\sum_{i, j=0}^{N-1} p_{i, j} \frac{\left(i-\mu_{i}\right)\left(j-\mu_{j}\right)}{\sqrt{\sigma_{i}^{2} \sigma_{j}^{2}}}
$$

4. Varians

Varians GLCM menunjukkan sebaran nilai piksel pada bidang citra[23].

$$
\begin{array}{r}
\sigma_{i}^{2}=\sum_{i, j=0}^{N-1} p_{i, j}\left(i-\mu_{i}\right)^{2} ; \\
\sigma_{j}^{2}=\sum_{i, j=0}^{N-1} p_{i, j}\left(i-\mu_{j}\right)^{2}
\end{array}
$$

\section{IDM (Inverse Difference Moment)}

Mengukur homogenitas. Nilai ini sangat sensitif terhadap nilai disekitar diagonal utama. Bernilai tinggi ketika semua pixel mempunyai nilai yang sama/seragam. Kebalikan dari contrast yaitu akan bernilai besar jika mempunyai nilai pixel yang sama pada saat energy bernilai tetap.

$$
I D M=\sum_{i, j=0}^{N-1} \frac{p(i, j)}{1+(i-j)^{2}}
$$

6. Entropy

Mengukur kompleksitas (keacakan) citra. Entropy akan bernilai tinggi ketika citra tidak seragam.

$$
\text { Entropy }=-\sum_{i, j=0}^{N-1} p(i, j) \log (i, j)
$$

\section{METODOLOGI}

Proses akuisisi citra dilakukan dengan menggunakan kamera (smartphone camera). Sebelum proses akuisisi, telur ayam kampung dilakukan proses candling (peneropongan dengan sinar) menggunakan senter. Hasil yang diperoleh dari akuisisi citra ini adalah gambar citra RGB dari telur ayam candling.

Histogram dari masing-masing citra warna akan memberikan nilai dengan 3 nilai intensitas yang berbeda yaitu Merah, Hijau, dan Biru. Sehingga perlu dilakukan proses konversi kedalam citra grayscale untuk proses GLCM. 


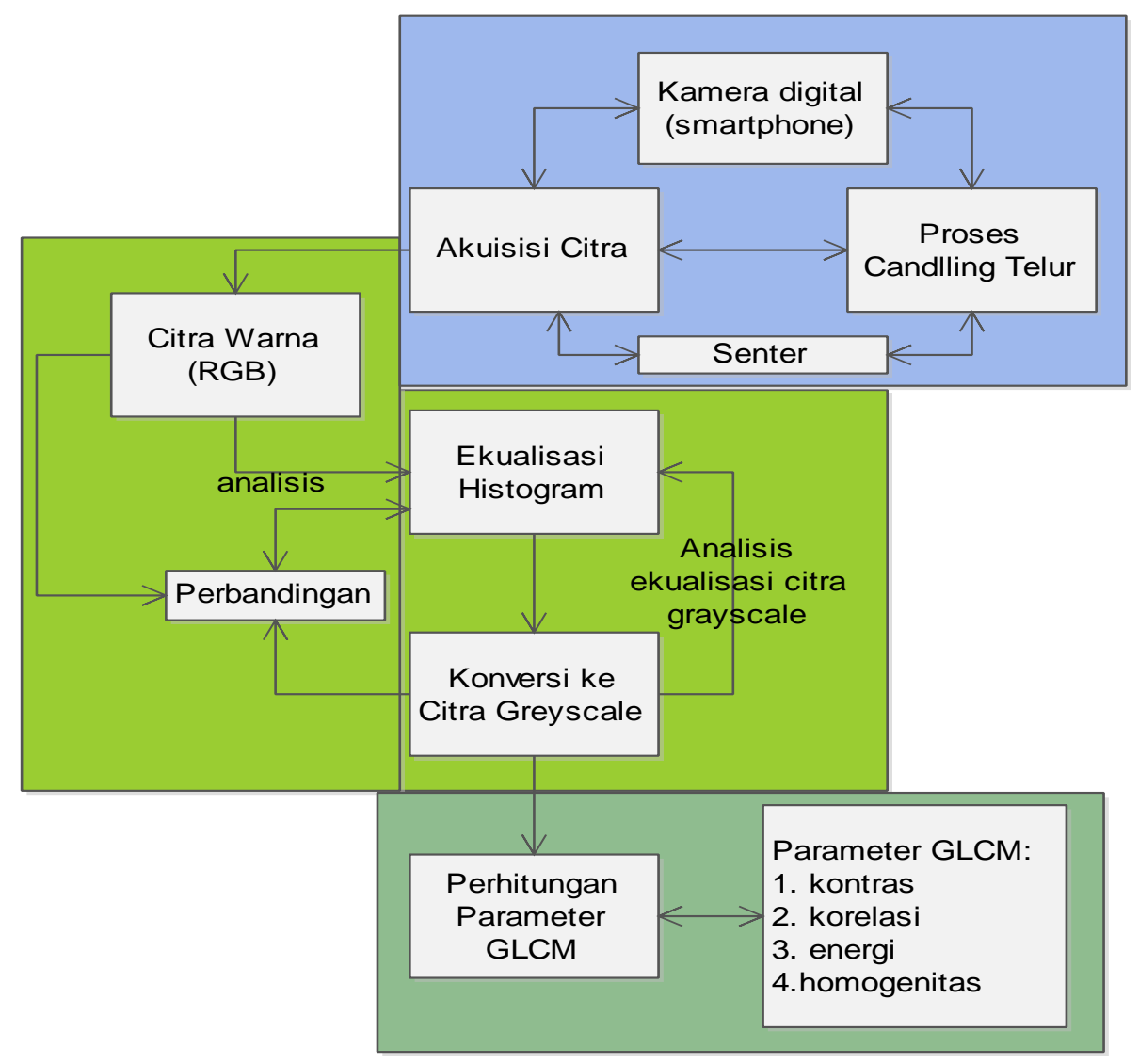

Gambar 4. Alur Proses Analisis GLCM pada Fertilitas Telur

Perhitungan GLCM dilakukan dengan 6 parameter (ASM, Kontras, Korelasi, Varians, IDM, dan Entropy). Citra telur ayam kampung akan memberikan nilai dari masing-masing nilai parameter tersebut. Parameter tersebut akan menjadi acuan dalam penentuan fertilitas telur ayam.

\section{HASIL DAN PEMBAHASAN}

Proses yang dilakukan berdasarkan metodologi penelitian menghasilkan beberapa point penting diantaranya adalah:

\subsection{Analisis Akuisisi Citra}

Akuisisi citra dilakukan dengan menggunakan kamera smartphone. Rancangan desain alat yang digunakan adalah seperti pada Gambar 5.

Proses candling telur ayam (seperti dalam rancangan Gambar 5) dilakukan dengan tujuan untuk mengetahui fertilitas telur ayam (khususnya dalam penelitian ini adalah telur ayam kampung).
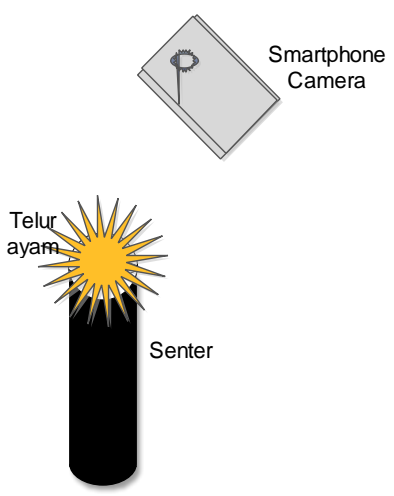

Gambar 5. Rancangan Proses Akuisisi Citra Candling Telur Ayam

Dalam proses candling akan menunjukkan bahwa telur ayam fertile ditandai dengan adanya pertumbuhan zigot/embriyo pada telur yang dilakukan proses penerangan dengan senter. Kemudian dilakukan proses capturing objek telur ayam kampung sehingga akan didapatkan gambar seperti Gambar 2. Proses ini dilakukan dengan menggunakan smartphone (kamera) untuk mengcapture telur ayam yang disinari 
dengan senter, dimana jarak antara kamera smartphone dengan objek yang akan dilakukan proses capturing tidak terlalu diperhitungkan.

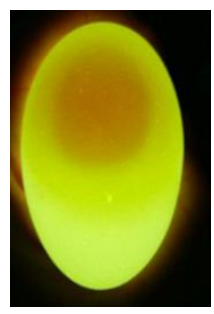

(a)

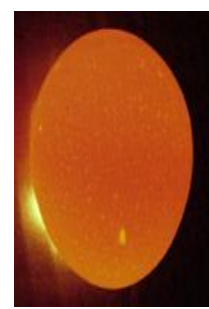

(b)
Gambar 6. Citra Telur Hasil Proses Candling (a) Telur Fertile [24], (b) Telur Tidak Fertile

\subsection{Histogram Ekualisasi}

Berdasarkan pada gambar citra hasil proses candling untuk telur fertile (Gambar 6.(a)) maka diperoleh gambar histogram citra warna (Gambar 7).

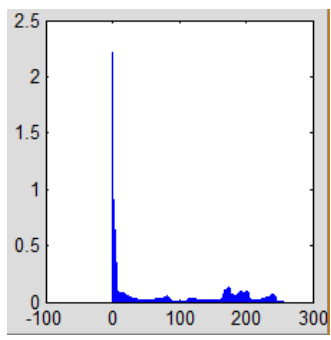

(a)

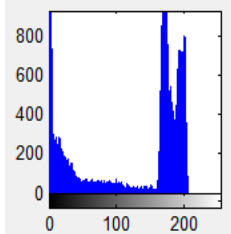

(b)

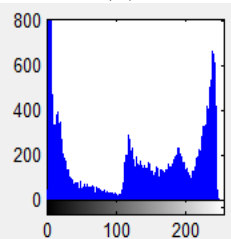

(c)

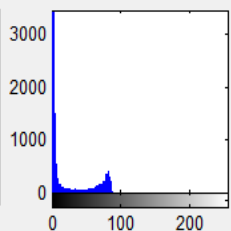

(d)
Gambar 7. Histogram (a) Citra Warna Telur Feritile, (b) Komponen Red, (c) Komponen Green, (d) Komponen Blue

Gambar 7 menunjukkan hasil histogram warna dari citra telur fertile (Gambar 7(a)) merupakan gabungan dari masing-masing komponen warna merah (7(b)), hijau (7(c)), dan biru (7(d)). Kemudian dari masing-masing warna pada citra RGB dilakukan konversi ke dalam citra grayscale menjasi 1 intensitas warna yaitu abu-abu dengan ukuran 8 bit (256) yang mempunyai range 0-255. Sehingga untuk histogramnya dapat diperoleh seperti Gambar 8.

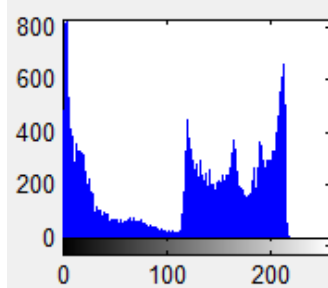

Gambar 8. Histogram Citra Greyscale Telur Fertile

Seperti halnya dengan citra telur fertile, citra telur tidak fertile juga memiliki gambar histogram warna (Gambar 9(a)) yang disusun dari 3 komponen warna secara berturut-turut merah (9(b)), hijau (9(c)) dan biru (9(d)) yang akan digabungkan menjadi 1 histogram warna.

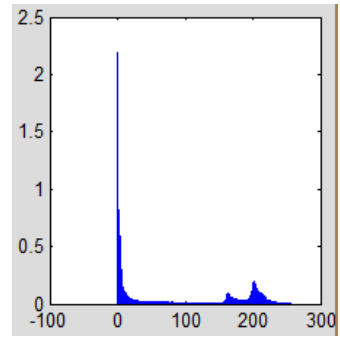

(a)

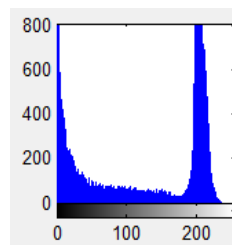

(b)

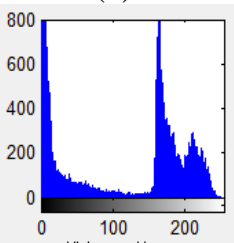

(c)

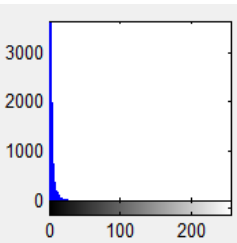

(d)
Gambar 9. Histogram (a). Citra Warna Telur Tidak Fertile, (b) Komponen Red, (c) Komponen Green, (d) Komponen Blue

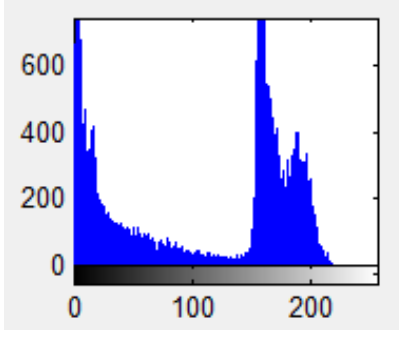

Gambar 10. Histogram Citra Grayscale 
Dari histogram warna Gambar 9 dikonversi menjadi grayscale menjadi seperti Gambar 10. Dimana hasil menunjukkan intensitas warna grayscale dengan range 0-255 dan frekuensi kemunculan setiap intensitas warna abu-abu terlihat seperti pada Gambar 10.

\subsection{Konversi Citra Warna ke Citra Grayscale dan Perhitungan Parameter GLCM}

Citra warna (RGB)perlu dilakukan konversi ke dalam citra greyscale untuk menghitung parameter metode GLCM. Parameter yang digunakan ada 6 yaitu ASM, Kontras, Korelasi, Varians, IDM dan Entropy.Hasil perhitungan beberapa citra sampel telur ayam kampung yang dilakukan candling dapat dilihat pada Tabel 1.

Agar memudahkan dalam melakukan analisis menggunakan grafik seperti Gambar 10, dalam penelitian ini dilakukan normalisasi dengan membagi bilangan sama untuk setiap komponen. Normalisasi yang dilakukan yaitu dengan membagi masing-masing komponen dengan nilai tertentu yang dapat memudahkan dalam analisis dan perhitungan. Hasil normalisasi terlihat pada Tabel 2.

Tabel 1. Perhitungan Parameter GLCM untuk 10 Sampel yang Dilakukan

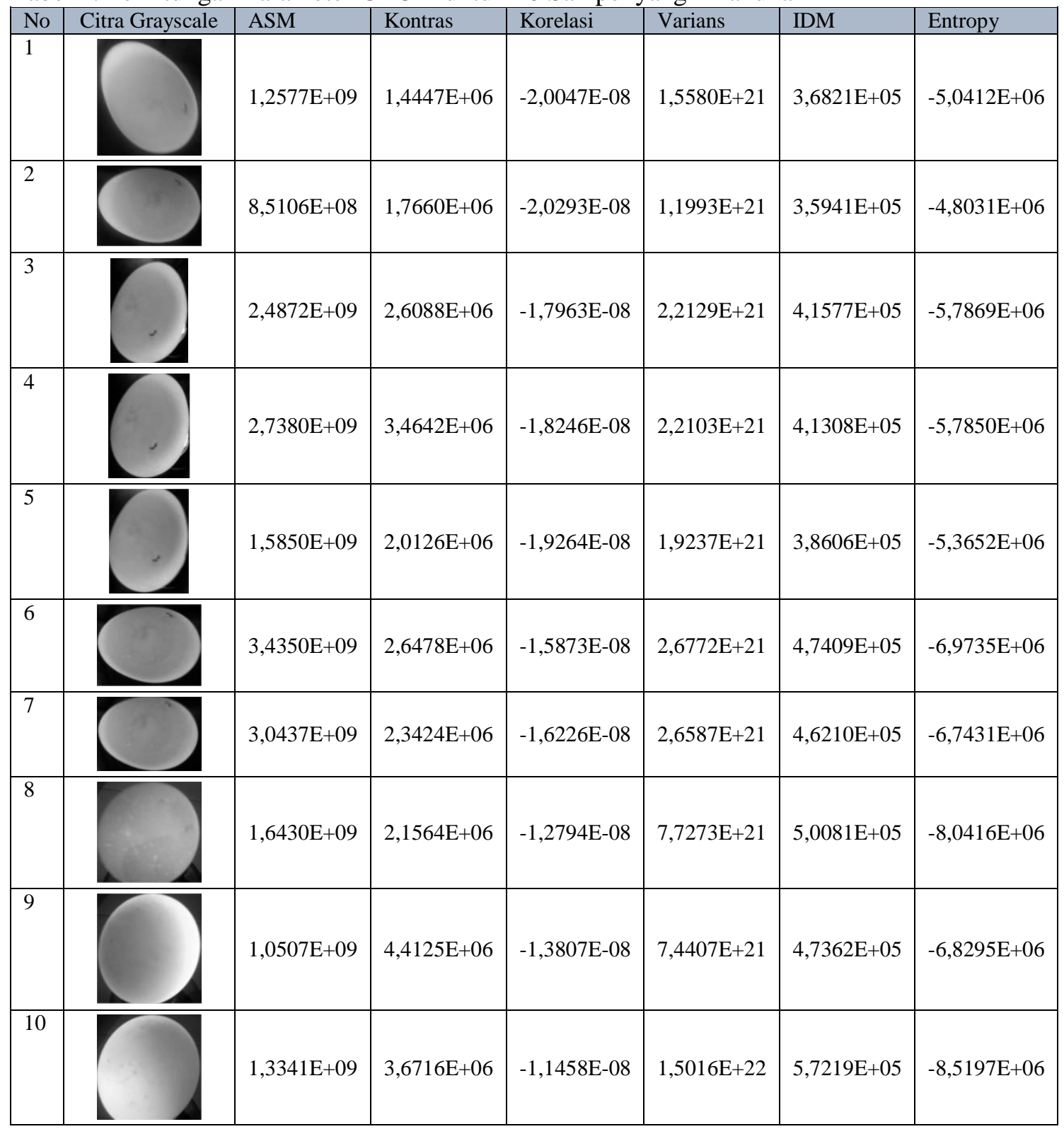


Tabel 2. Hasil Normalisasi Parameter GLCM

\begin{tabular}{|c|c|c|c|c|c|c|c|}
\hline Data & ASM & Kontras & Korelasi & Varians & IDM & Entropy & Fertilitas \\
\hline 1 & 1,258 & 1,445 & 2,005 & 1,558 & 3,682 & 5,041 & Fertile \\
\hline 2 & 0,851 & 1,766 & 2,029 & 1,199 & 3,594 & 4,803 & Fertile \\
\hline 3 & 2,487 & 2,609 & 1,796 & 2,213 & 4,158 & 5,787 & Fertile \\
\hline 4 & 2,738 & 3,464 & 1,825 & 2,210 & 4,131 & 5,785 & Fertile \\
\hline 5 & 1,585 & 2,013 & 1,926 & 1,924 & 3,861 & 5,365 & Fertile \\
\hline 6 & 3,435 & 2,648 & 1,587 & 2,677 & 4,741 & 6,974 & Fertile \\
\hline 7 & 3,044 & 2,342 & 1,623 & 2,659 & 4,621 & 6,743 & Fertile \\
\hline 8 & 1,643 & 2,156 & 1,279 & 7,727 & 5,008 & 8,042 & Infertile \\
\hline 9 & 1,051 & 4,413 & 1,381 & 7,441 & 4,736 & 6,829 & Infertile \\
\hline 10 & 1,334 & 3,672 & 1,146 & 15,016 & 5,722 & 8,520 & Infertile \\
\hline
\end{tabular}

Tabel 1 menunjukkan nilai perhitungan secara riil yang dilakukan dengan aplikasi. Dimana masing-masing parameter memberikan nilai yang berbeda. Nilai yang dihasilkan ada yang menunjukkan nilai positif dan negatif.

Pada Tabel 1, urutan nomor 1 sampai dengan 7 menunjuukan citra telur ayam yang dikelompokkan dalam kelompok telur fertile. Sedangkan urutan nomor 8 sampai dengan 10 menunjukkan citra telur ayam yang dikeompokkan dalam kelompok telur infertile.

Perhitungan rill (Tabel 1) perlu dilakukan proses normalisasi, sehingga diperoleh hasil pada Tabel 2. Proses ini digunakan untuk mempermudah dalam proses analisis masingmasing parameter dari nilai-nilai yang telah dihitung agar nilai yang dianalisis tidak terlalu besar dan tidak terlalu kecil. Proses nornalisasi dihasilkan nilai seperti pada Tabel 2. Norrmalisasi dilakukan dengan membagi dengan $10^{\mathrm{N}}$, dimana $\mathrm{n}$ menunjukkan jumlah digit terkecil dari masing-masing parameter. Dan jika nilai < 0 maka dikalikan dengan negatifnya. Sehingga berdasarkan Tabel 2 diperoleh grafik analisis perhitungan nilai parameter (Gambar 11) yang berbeda-beda.

\subsection{Analisis Hasil Perhitungan Parameter GLCM dalam Penentuan Fertilitas Telur Ayam Kampung}

Gambar 11 menunjukkan grafik dari perhitungan GLCM untuk semua parameter. Masing-masing parameter memberikan nilai dan gambar yang berbeda, sehingga dapat diketahui perbedaan dari masing-masing nilai parameter tersebut.

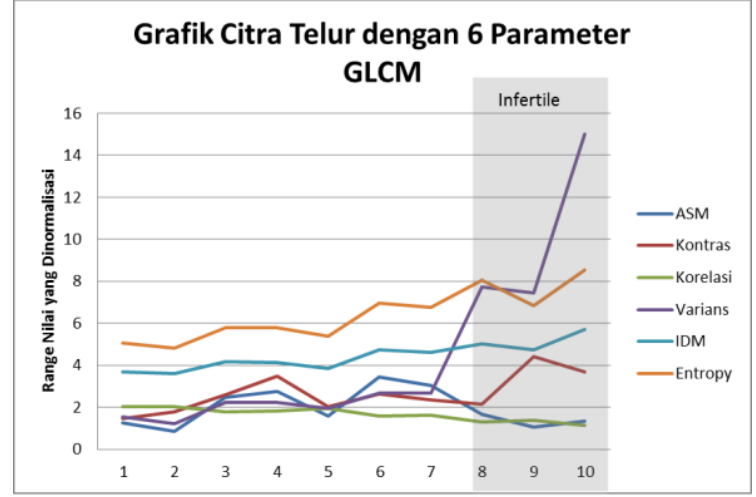

Gambar 11. Grafik Perhitungan 6 Parameter GLCM

Secara signifikan, nilai varians menunjukkan nilai perbedaan yang sangat tinggi antara telur fertile dan infertile (telihat pada Gambar 11 ditunjukkan pada grafik warna ungu). Sementara parameter yang lain (ASM, Kontras, Korelasi, IDM, dan Entropy) juga memberikan nilai yang berbeda antara telur yang fertile dan infertile akan namun tidak begitu terlihat secara jelas, perlu pengamatan yang lebih (dari Gambar 11). Hal ini dikarenakan parameter-parameter tersebut memiliki nilai yang hampir sama/mendekati untuk beberapa sampel yang digunakan.

\section{KESIMPULAN}

Proses akusisi candling telur ayam menghasilkan citra warna (RGB). Kualitas citra yang diperoleh sangat bergantung pada kamera dan senter yang digunakan. Semakin terang dan tinggi kualitas kamera yang digunakan maka akan memberikan nilai yang lebih jelas dalam proses identifikasi telur menggunakan GLCM. 
Semakin tinggi kualitas citra yang dihasilkan maka akan memberikan nilai histogram yang sama atau tidak terlalu jauh berbeda dari masingmasing citra yang dihasilkan.

Histogram yang diperoleh dari proses akuisisi memberikan 3 nilai intensitas untuk masing-masing warna maka perlu dilakukan konversi menjadi citra grayscale untuk proses GLCM. GLCM merupakan metode ekstraksi ciri yang menggunakan beberapa parameter menggunakan beberapa parameter yaitu ASM, Kontras, Korelasi, Varians, IDM, dan Entropy. Proses GLCM memberikan nilai yang berbeda pada telur fertile dan infertile. Sehingga metode GLCM dapat digunakan sebagai acuan dalam proses indetifikasi fertilitas telur ayam kampung.

\section{DAFTAR PUSTAKA}

[1] Ebta Setiawan, "KBBI," http://kbbi.web .id/jadwal, 2012. [Online].

[2] SITUS-PETERNAKAN.COM, "Kumpulan Artikel Peternakan I SitusPeternakan.Com," 18 June 2014. [Online]. Available: http://www.situspeternakan.com/2014/06/tentang-ayamkampung-asli-indonesia.html. [Accessed 8 February 2017].

[3] I. -. P. UNDP, "Kajian Ayam Buras dengan Pendekatan Rantai Nilai dan Iklim Usaha di Kabupaten Boven Digoel," Program Pembangunan berbasis Masyarakat Fase II: Implementasi Institusionalisasi Pembangunan Mata Pencaharian yang Lestari untuk Masyarakat Papua, Papua, 2013.

[4] "Sehatituharus," Ini Cara Mengetahui Telur yang Sehat, 5 2015. [Online]. Available: http://www.sehatituharus.com /2015/05/ini-cara-mengetahui-telur-yangsehat.html. [Accessed 92 2017].

[5] "SENTRALTERNAK," Distributor Bibit dan Peralatan Ternak, 1342009. [Online]. Available: http://sentralternak. com/index.php/2009/04/13/agarpenetasan-kita-berhasil/. [Accessed 92 2017].

[6] "wiraternak.com," Informasi wirausaha peternakan, 4 2012. [Online]. Available: http://www.wiraternak.com/2012/04/ciriciri-telur-tetas-yang-fertil-atau.html.

[Accessed 92 2017].
[7] I. Hestiningsih, "Pengolahan Citra," [Online]. Available: http://27afrilfile.weebly.com/uploads/1/3/0/7/1307722 6/pengolahan-citra.pdf. [Accessed 92 2017].

[8] Yustina Retno Arum Utami, "Pengenalan Telur Berdasarkan Karakteristik Warna Citra," Jurnal Ilmiah SINUS, vol. 7, no. 2, pp. 1-14, 2009.

[9] T. A. Wijaya and P. Yudi, "Implementasi Visi Komputer Dan Segmentasi Citra Untuk Klasifikasi Bobot Telur Ayam Ras," in Seminar Nasional Aplikasi Teknologi Informasi 2010, 2010.

[10] L. Liu; M. O. Ngadi, "Detecting Fertility and Early Embryo Development of Chicken Eggs Using Near-Infrared Hyperspectral Imaging," Springer, vol. Food Bioprocess Technol (2013), no. 6, pp. 2503-2513, 2012.

[11] C.-S. Lin, P. T. Yeh, D.-C. Chen, Y.-C. Chiou and C.-H. Lee, "The Identification and Filtering of Fertilized Eggs with a Thermal Imaging System," Computers and Electronics in Agriculture, vol. Computers and Electronics in Agriculture (2013), no. 91, pp. 94-105, 2012.

[12] M. A. Khabibulloh, A. Kusumawardhani and D. Y. Pratama, "Rancang Bangun Sistem Deteksi Embrio pada Telur Menggunakan Webcame," Jurnal Teknik Pomits, vol. 1, no. 1, pp. 1-6, 2012.

[13] I. Ruslianto, "Klasifikasi Telur Ayam Dan Telur Burung Puyuh Menggunakan Metode Connected Component Analysis," Jurnal Ilmiah SISFOTENIKA, vol. 3, no. 1, pp. 41-50, 2013.

[14] P. R. Trisnaningtyas and Maimunah, "Klasifikasi Mutu Telur Berdasarkan Kebersihan Kerabang Telur Menggunakan K-Nearest Neighbor," in Konferensi Nasional Informatika (KNIF), 2015.

[15] O. D. Nurhayati, "Sistem Analisis Tekstur Secara Statistik Orde Pertama Untuk Mengenali Jenis Telur Ayam Biasa dan Telur Ayam Omega-3," Jurnal Sistem Komputer, vol. 5, no. 2, pp. 79-82, 2015.

[16] L. Hai-ling, C. Jian-rong, S. Li, Y. Leiming and L. Meng-lei, "Research on the Discrimination of Hatching Eggs Activity Based on Thermal Imaging: A Food Nondestructive Testing Practice," 
International Journal of Smart Home, vol. 10, no. 2, pp. 175-186, 2016.

[17] Cholifah, Siti; Prasetyawan, Yudha, "Perancangan Sistem Identifikasi Fertilitas dan Daya Tetas Telur Itik Berbasis Digital Image Processing," Institut Teknologi Sepuluh Nopember (ITS) Surabaya (Teknik Industri).

[18] H. R. Rukmana, Ayam Buras Intensifikasi dan Kiat Pengembangan, Yogyakarta: Kanisius, 2003.

[19] D. Putra, Pengolahan Citra Digital, Yogyakarta: ANDI, 2010 (Ed.I).

[20] metode-algoritma.com, "MetodeALgoritma.com," 7 2015. [Online]. Available: http://www.metodealgoritma.com/2015/07/metodepenyetaraan-histogram.html. [Accessed $1912017]$.

[21] D. Gadkari, "IMAGE QUALITY ANALYSIS USING GLCM," Master of Science in Modeling and Simulation in the College of Arts and Sciences at the University of Central Florida (Fall Term), Orlando, Florida, 2004.

[22] softscients.web.id, "IT Outsourcing Service - Software - Research," 1852015. [Online]. Available: http: //www . softscients.web.id/2015/01/glcm-analisistekstur-citra-digital.html.[Accessed 1/ 1 /
2017].

[23] C. Lubis, A. B. Dharmawan and M. Ang, "Automatic Cropping pada Pengenalan Naskah Braille," in Seminar Nasional Teknologi Informasi dan Multimedia 2015, Yogyakarta, 2015.

[24] N. Stuff. [Online]. Available: http://www.nifty-stuff.com/candlingeggs.php. [Accessed 149 2016].

\section{Biodata Penulis}

Shoffan Saifullah, Mahasiswa Magister Teknik Informatika, Universitas Ahmad Dahlan. Telah menyelesaikan S1 di Universitas Teknologi Yogyakarta dan sekarang bekerja sebagai Sekretaris Prodi di Fakultas Sains dan Teknologi, Universitas Teknologi Yogyakarta. Ketertarikan dalam bidang Artificial Intelligent dan Computer Vision and Image Processing.

Sunardi, S.T., M.T., Ph.D, Dosen Teknik Elektro dan Magister Teknik Informatika, Universitas Ahmad Dahlan. Dan menjabat sebagai Kaprodi Magister Teknik Informatika, Univerisitas Teknologi Yogyakarta.

Anton Yudhana, S.T., M.T., Ph.D, Dosen Teknik Telektro dan Mahasiswa Magister Teknik Informatika, Universitas Ahmad Dahlan. 